\title{
ChemComm
}

Check for updates

Cite this: Chem. Commun., 2019,

55,1148

Received 5th December 2018,

Accepted 4th January 2019

DOI: $10.1039 / \mathrm{c} 8 \mathrm{cc} 09659 \mathrm{~g}$

rsc.li/chemcomm

We report the sensitivity of the membrane asymmetry of $A B C$ (PEO-b-PCL-b-PMOXA) polymersomes towards the end-group modification of a shorter $C$ block. While a non-modified $A B C$ polymer formed polymersomes with the $A$ block outside and the $C$ block inside, a mixture of $A B C$ and $A B C$-biotin formed polymersomes with the $C$ block outside.

Polymersomes have received considerable attention due to their diverse applications, including drug delivery and artificial nanoreactors. ${ }^{1-5}$ Typically, polymersomes have a symmetric membrane because they are formed by $\mathrm{AB}^{6-10}$ or $\mathrm{ABA}^{12}$ block copolymers, where $\mathrm{A}$ is a soluble block and $\mathrm{B}$ is a non-soluble block. Polymersomes assembled from ABC block copolymers, where the $\mathrm{A}$ and $\mathrm{C}$ blocks are soluble, have an asymmetric membrane with a longer soluble block forming the outer surface, and a shorter one forming the inner surface of the polymersomes. ${ }^{3}$ Such membrane asymmetry offers several advantages for the design of sophisticated structures. First of all, membrane asymmetry is an important step towards mimicking natural asymmetric cell membranes, ${ }^{13,14}$ and $\mathrm{ABC}$ membranes have been shown to be beneficial for the directed insertion of transmembrane proteins. ${ }^{15,16}$ Depending on the nature of the A and $\mathrm{C}$ blocks, asymmetry can result in different properties of the inner and outer surface of polymersomes. For example, one of the two hydrophilic blocks can be charged, thus resulting in an asymmetric membrane carrying a charge only on one side of the membrane, which consequently leads to different affinity to proteins and enhancement of drug delivery. ${ }^{17-21}$ In addition,

\footnotetext{
${ }^{a}$ Department of Physical Chemistry, University of Basel, Mattenstrasse 24a, BPR 1096, 4058 Basel, Switzerland. E-mail: wolfgang.meier@unibas.ch

${ }^{b}$ Precision Macromolecular Chemistry, Institute Charles Sadron, UPR-22 CNRS, BP 84047, 23 rue du Loess, 67034 Strasbourg Cedex 2, France.

E-mail:ev.konishcheva@gmail.com

$\dagger$ Electronic supplementary information (ESI) available: Experimental details, characterization of polymers, ${ }^{1} \mathrm{H}$ NMR of ABC-biotin, LSM of polymersomes formed by $\mathrm{ABC}$ and biotinylated polymers, FCS of $\mathrm{ABC}$ labeled with Bodipy $630 / 650$, calculation of polymersome volume, and LSM of cloud-like aggregates. See DOI: $10.1039 / \mathrm{c} 8 \mathrm{cc} 09659 \mathrm{~g}$
}

an asymmetric membrane can carry different functional groups on the inner and outer surfaces ${ }^{11}$ for subsequent selective modifications of either side of the membrane.

The asymmetry of $\mathrm{ABC}$ membranes is a consequence of the packing parameter ${ }^{22}$ (i.e., geometric shape occupied by polymer chains) and incompatibility of the two soluble blocks. ${ }^{11,15,23,24}$ It is believed that the packing parameter plays a predominant role in the formation of membrane asymmetry, and even blocks of the same nature but different lengths segregate on different sides of the membrane. ${ }^{25}$ The packing parameter is very sensitive to slight changes in the block ratio caused by the variation of hydrophilicity/hydrophobicity under external stimuli or chemical modification. For example, structures assembled from stimulusresponsive polymers may undergo order-order transitions (e.g., polymersome-to-worm, polymersome-to-micelle) upon the change of temperature ${ }^{26-33}$ or $\mathrm{pH}^{3,{ }^{34-36}}$ in the presence of enzymes,${ }^{37}$ by host-guest recognition ${ }^{38}$ or in the presence of a cross-linking agent, ${ }^{39}$ etc. Moreover, even the modification of only end-groups already induces morphological transitions. ${ }^{40-42}$ Thus, one might expect that the packing parameter of $\mathrm{ABC}$ molecules, and therefore the molecule orientation within the polymersome membrane, may be affected by end-group modification. To test this hypothesis, in the present study we probe the sensitivity of the membrane asymmetry of $\mathrm{ABC}$ polymersomes towards the end-group modification of a shorter hydrophilic block located inside.

As a model system, we chose polymersomes formed by poly(ethylene oxide)-block-polycaprolactone-block-poly(2-methyl2-oxazoline) $\left(\mathrm{PEO}_{45}-b\right.$ - $\mathrm{PCL}_{110}-b$ - $\left.\mathrm{PMOXA}_{4}=\mathrm{ABC}\right)$ in an aqueous solution. ${ }^{11}$ These polymersomes have an asymmetric membrane with a longer A (PEO) block located outside and a shorter C block (PMOXA) located inside, which was proven by two independent methods. These $\mathrm{ABC}$ polymersomes stayed intact during at least 6 months of storage at room temperature. To increase the length of the $\mathrm{C}$ block by its end-group modification, a biotin moiety was attached to the $\mathrm{ABC}-\mathrm{N}_{3}\left(\mathrm{PEO}_{45}-b-\mathrm{PCL}_{103}-b-\mathrm{PMOXA}_{4}-\mathrm{N}_{3}\right)$ polymer resulting in ABC-biotin. As a control, we synthesized biotin$\mathrm{ABC}$ (biotin- $\mathrm{PEO}_{45}-b-\mathrm{PCL}_{100}-b-\mathrm{PMOXA}_{4}$ ). ABC polymers were 

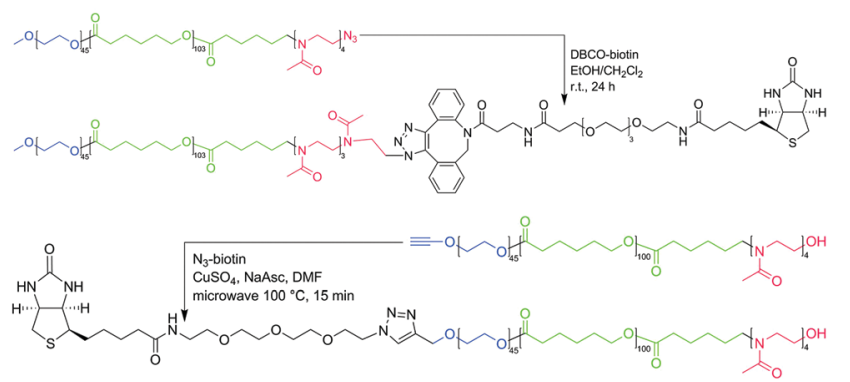

Fig. 1 Scheme of synthesis of ABC-biotin (obtained via Cu-free DBCO azide coupling) and biotin- $A B C$ (obtained via microwave-assisted CUAAC) used in this study.

synthesized via coordination-insertion ring-opening polymerization of $\varepsilon$-caprolactone on a PEO macroinitiator followed by $\omega$-tosylation and subsequent cationic ring-opening polymerization of 2-methyl-2-oxazoline as described previously (see ESI $\dagger$ ). ${ }^{11,43}$ The ABC-biotin polymer was synthesized via coupling between DBCO-biotin and $\mathrm{ABC}-\mathrm{N}_{3}$; the biotin-ABC polymer was synthesized via $\mathrm{Cu}(\mathrm{I})$-catalyzed azide-alkyne cycloaddition (CuAAC) between alkyne-ABC and biotin- $\mathrm{N}_{3}$ (Fig. 1).

ABC-biotin synthesis proceeded smoothly at room temperature, which was confirmed by the appearance of the peaks characteristic for biotin and disappearance of the signal from the methylene group next to azide in the ${ }^{1} \mathrm{H}$ NMR spectrum (Fig. S1, ESI $\dagger$ ). Attachment of biotin could not be determined quantitatively from the ${ }^{1} \mathrm{H}$ NMR spectrum due to only partial solubility of biotin in $\mathrm{CDCl}_{3}$ or DMF- $\mathrm{d}_{7}$, which meant that the signals from this group were rather low. However, we assumed that $100 \%$ of $\mathrm{ABC}-\mathrm{N}_{3}$ converted into ABC-biotin, because we used 5 -fold excess of DBCO-biotin, and the signal from the methylene group next to the azide disappeared completely. Commercially available kits for biotin quantification were not applicable to our system, since the detection implies enzymatic reaction performed in aqueous solution.

Modification of $\mathrm{ABC}$ from the $\mathrm{C}$ (PMOXA) terminus is a relatively simple process, because the polymerization of PMOXA is the last step in the synthesis. Several functional groups can be obtained by quenching the polymerization with a specific reagent. ${ }^{44}$ Introduction of the functional group on the A (PEO) terminus is more demanding due to possible interference of such group with subsequent synthetic steps and a limited number of commercially available heterobifunctional PEO macroinitiators. We chose an alkyne-PEO-OH macroinitiator, since the alkyne group was inert in the subsequent synthetic steps, and an $\mathrm{OH}$ group was required for polymerization of $\varepsilon^{-}$ caprolactone. $\mathrm{N}_{3}$-biotin was then attached to alkyne-ABC via CuAAC, frequently used in organic chemistry and biochemistry due to high yields and a wide range of applicable conditions. ${ }^{45,46}$ However, the reaction between $\mathrm{N}_{3}$-biotin and alkyne-ABC did not proceed under different tested conditions (e.g., catalytic systems containing different $\mathrm{Cu}(\mathrm{I})$ and $\mathrm{Cu}(\mathrm{II})$ salts and ligands; $T=20-100{ }^{\circ} \mathrm{C}$; solvents: DMF, $\mathrm{CH}_{2} \mathrm{Cl}_{2} / \mathrm{EtOH}$, THF, THF $/ \mathrm{H}_{2} \mathrm{O}$; $t=1-13$ days). Finally, we tested microwave-assisted synthesis, since it was shown to be advantageous for coupling of alkyne-PCL and heptakis-azido- $\beta$-cyclodextrin by Hoogenboom et al. ${ }^{47}$ Already after 15 min under microwave irradiation at $100{ }^{\circ} \mathrm{C}$ we obtained a biotin-ABC polymer. Similar to ABC-biotin, the percentage of functionalization of biotin- $\mathrm{ABC}$ could not be determined from integration of the signals from the biotin group on the ${ }^{1} \mathrm{H}$ NMR spectrum, but the conversion was assumed to be $100 \%$ due to the disappearance of the signal from the methylene group next to the alkyne (data not shown).

The synthesized ABC-biotin/biotin-ABC polymers were blended with $\mathrm{ABC}$ at different ratios $(1,5$, and $10 \mathrm{w} / \mathrm{w} \%)$ prior to aqueous self-assembly using the film rehydration method at $62{ }^{\circ} \mathrm{C}$. The final polymer concentration after self-assembly was $2 \mathrm{mg} \mathrm{mL}{ }^{-1}$. The presence of biotinylated polymers did not affect the formation of polymersomes (Fig. S2, ESI $\dagger$ ).

To detect biotin on the outer surface of polymersomes, aqueous solutions of polymersomes and Cy5-labeled streptavidin (Cy5-SA) were mixed at $20{ }^{\circ} \mathrm{C}$ prior to fluorescence correlation spectroscopy (FCS) ${ }^{48}$ experiments and laser scanning microscopy (LSM) imaging. The final Cy5-SA concentration was $0.05 \mathrm{mg} \mathrm{mL}^{-1}$, and the final polymer concentration was $1 \mathrm{mg} \mathrm{mL} \mathrm{m}^{-1}$. This corresponds to $\sim 1000$-fold excess of biotin over Cy5-SA in the case of $1 \%$ of ABC-biotin. Such excess was chosen to ensure the efficient binding of Cy5-SA to avoid background noise in the LSM images caused by Cy5-SA in solution. In addition, the latter ratio was optimal, because the higher Cy5-SA concentration led to its aggregation, and the lower concentration of polymersomes resulted in an insufficient number of events detected during FCS measurements.

We measured aqueous solutions containing only Cy5-SA (reference), ABC polymersomes and Cy5-SA (negative control), $\mathrm{ABC}+$ biotin-ABC polymersomes and Cy5-SA (positive control), and $\mathrm{ABC}+\mathrm{ABC}-$ biotin polymersomes and Cy5-SA. Samples containing only Cy5-SA or ABC polymersomes with Cy5-SA showed similar responses (Fig. 2a, black and green curves). The latter indicates no unspecific binding of Cy5-SA to polymersomes or its penetration inside them. The absence of unspecific binding was also confirmed by the lack of fluorescent polymersomes in LSM images (Fig. 2b). This non-interactive behavior can be attributed to the protein-repellent nature of both hydrophilic blocks (i.e., PEO and PMOXA). ${ }^{49,50}$

Samples containing polymersomes with biotinylated polymers and Cy5-SA exhibited increased diffusion times (Fig. 2a, red and blue curves), which confirmed binding of the protein molecules to such polymersomes. Similar diffusion times were obtained for $\mathrm{ABC}$ polymersomes stained with hydrophobic Bodipy 630/650 dye (Fig. S3, ESI†). The percentage of bound Cy5-SA was $\sim 40-60 \%$ (Table 1 ) and did not depend on the amount $(1 \%, 5 \%, 10 \%)$ of ABC-biotin/biotin-ABC polymers. Longer incubation time (up to $48 \mathrm{~h}$ ) yielded similar results.

The presented FCS data qualitatively indicated the presence of biotin moieties on the outer surface of polymersomes, but could not be used for quantitative analysis because of the large sizes of polymersomes (Table 1). The typical confocal volume in FCS is $\sim 1 \mathrm{fL},{ }^{51,52}$ whereas the average volume of polymersomes is $\sim 30 \mathrm{fL}$ (see ESI $\dagger$ ). Besides, FCS measurements were complicated by fast sedimentation and aggregation of polymersomes. 


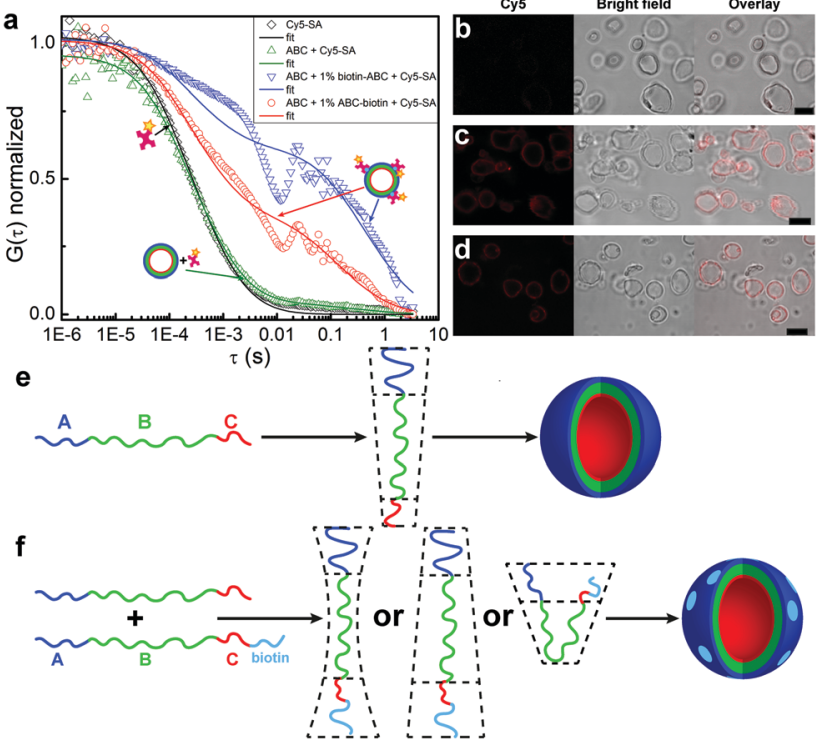

Fig. 2 Binding between polymersomes and Cy5-SA. (a) Normalized autocorrelation curves from FCS data in water: $0.05 \mathrm{mg} \mathrm{mL}^{-1}$ Cy5-SA (black), $0.05 \mathrm{mg} \mathrm{mL}^{-1} \mathrm{Cy} 5-\mathrm{SA}$ and $1 \mathrm{mg} \mathrm{mL}^{-1} \mathrm{ABC}$ polymersomes (green curve, image b), $0.05 \mathrm{mg} \mathrm{mL}^{-1} \mathrm{Cy} 5-\mathrm{SA}$ and $1 \mathrm{mg} \mathrm{mL}^{-1}$ polymersomes formed by $A B C$ containing $1 \%$ of biotin- $A B C$ (blue curve, image $\mathrm{c}$ ), $0.05 \mathrm{mg} \mathrm{mL}^{-1}$ Cy5-SA and $1 \mathrm{mg} \mathrm{mL}^{-1}$ polymersomes formed by $\mathrm{ABC}$ containing $1 \%$ of ABC-biotin (red curve, image d). The LSM, bright field, and overlay images $(b-d)$ were obtained under identical microscope settings. Scale bars are 5 $\mu \mathrm{m}$. Schematic representation of the packing geometry of (e) $A B C^{11}$ and (f) $A B C$-biotin molecules. Note, the actual distribution (homogenous or domain-forming) of biotin along the membrane remains unclear; the light blue domains are drawn for simplicity reason.

Table 1 Average diameters of polymersomes determined from LSM images and fraction of Cy5-SA bound to polymersomes determined from FCS experiments

\begin{tabular}{lll}
\hline Sample & $\begin{array}{l}D \text { of polymersomes, } \\
\mu \mathrm{m}\end{array}$ & $\begin{array}{l}\text { Fraction of Cy5-SA bound } \\
\text { to polymersomes, \% }\end{array}$ \\
\hline $\mathrm{ABC}$ & $4.2 \pm 1.6$ & $4 \pm 1$ \\
$\mathrm{ABC}+1 \%$ biotin-ABC & $3.4 \pm 1.2$ & $53 \pm 18$ \\
$\mathrm{ABC}+1 \%$ ABC-biotin & $3.8 \pm 1.5$ & $42 \pm 12$
\end{tabular}

As can be seen from Fig. 2a, the autocorrelation curves of the samples with $\mathrm{ABC}$-biotin/biotin-ABC contain some spikes at the diffusion time $>0.01 \mathrm{~s}$.

The FCS data were supported by LSM imaging (Fig. 2b-d). Non-biotinylated polymersomes stayed non-fluorescent in the presence of Cy5-SA, whereas the membranes of biotinylated polymersomes became fluorescent due to the binding of Cy5-SA. The latter indicates that binding happens only between the membrane and the protein and excludes the penetration of Cy5-SA inside the polymersomes.

As can be seen from the FCS and LSM data, the attachment of biotin to the shorter C (PMOXA) block results in its appearance on the outer surface of polymersomes. The "flip" of the $\mathrm{C}$ block from the inside to the outside can be a consequence of geometric and/or physico-chemical factors. The geometric factor implies the change of the packing shape occupied by ABC-biotin molecules compared to ABC. The physico-chemical factor implies the favored interactions between the A and C-biotin hydrophilic blocks. For example, it could be the interaction between the A (PEO) block and PEO spacer between $\mathrm{C}$ and biotin in ABC-biotin polymers (Fig. 1). Regardless of which factor dominates the "flip" of the C block, the only molecules that undergo such transition should be those containing biotin, i.e., ABC-biotin.

We believe that the geometric factor plays a predominant role, ${ }^{25}$ because the counter length of the biotinylated PMOXA block ( $230 \AA, 1090 \mathrm{~g} \mathrm{~mol}^{-1}$ ) was twice as long as that of nonbiotinylated PMOXA $\left(\sim 15 \AA, 340 \mathrm{~g} \mathrm{~mol}^{-1}\right)$. Our hypothesis is supported by self-assembly of pure ABC-biotin polymer: while non-modified $\mathrm{ABC}$ self-assembles into polymersomes (packing shape is a cylinder, Fig. 2e), pure ABC-biotin forms a mixture of polymersomes and cloud-like aggregates (double-cone packing shape, Fig. 2f and Fig. S4, ESI $\dagger$ ). ${ }^{53}$ The packing geometry of ABC-biotin chains in I-shaped conformation is most likely intermediate between cylinders and double-cone shape. U-shaped conformation is also possible, but less likely because ABC polymersomes contain predominantly molecules in the I-shaped conformation, ${ }^{11}$ and the structures formed by $\mathrm{ABC}$ molecules in the U-shaped conformation (e.g., worms) were not thermodynamically stable and transformed into polymersomes. ${ }^{53}$ The conformation of ABC-biotin molecules might be investigated by measuring spatial interactions between A (PEO) and C (PMOXA) blocks by 2D nuclear Overhauser effect spectroscopy (NOESY NMR) or Förster resonance energy transfer (FRET). NOESY NMR was not applicable to our system presumably due to the large size of the polymersomes, as we have already tested earlier. ${ }^{11}$ FRET experiments imply the presence of two fluorescent dyes, donor and acceptor, on the $\mathrm{A}$ and $\mathrm{C}$ ends in one $\mathrm{ABC}$-biotin molecule. In this case the final polymer should have a sequence donor-ABC-biotinacceptor. This would not only be a very demanding synthetic procedure, but more importantly, such molecules might have a completely different orientation in the membrane, as already biotin affects the membrane asymmetry. The amount, conformation (i.e., I- or U-shape), and distribution (i.e., homogenous or domainforming) of ABC-biotin molecules in the membrane could not be investigated with the conventional LSM or FCS due to their limitations, and thus these issues will be studied further elsewhere.

The experimental data presented here suggest that one should carefully consider the end-group modification of ABC polymers with respect to the membrane asymmetry. To conclude that the presented findings can be regarded as a general rule, other $\mathrm{ABC}$ systems of different chemical nature, block lengths, and polymersome size should be systematically investigated. Also, another question which should be addressed next is whether the asymmetry is influenced by in situ end-group modification, i.e., when the end-group modification is performed on already assembled polymersomes.

We acknowledge SNSF, NCCR Molecular Systems Engineering, and the University of Basel for financial support.

\section{Conflicts of interest}

There are no conflicts to declare. 


\section{References}

1 D. E. Discher and A. Eisenberg, Science, 2002, 297, 967-973.

2 C. G. Palivan, R. Goers, A. Najer, X. Zhang, A. Car and W. Meier, Chem. Soc. Rev., 2016, 45, 377-411.

3 A. Blanazs, S. P. Armes and A. J. Ryan, Macromol. Rapid Commun., 2009, 30, 267-277.

4 S. F. M. van Dongen, M. Nallani, J. J. L. M. Cornelissen, R. J. M. Nolte and J. C. M. van Hest, Chem. - Eur. J., 2009, 15, 1107-1114.

5 J. Rodríguez-Hernández, F. Chécot, Y. Gnanou and S. Lecommandoux, Prog. Polym. Sci., 2005, 30, 691-724.

6 B. M. Discher, Y.-Y. Won, D. S. Ege, J. C.-M. Lee, F. S. Bates, D. E. Discher and D. A. Hammer, Science, 1999, 284, 1143-1146.

7 S. Jain and F. S. Bates, Science, 2003, 300, 460-464.

8 J. A. Zupancich, F. S. Bates and M. A. Hillmyer, Macromolecules, 2006, 39, 4286-4288.

9 P. P. Ghoroghchian, G. Li, D. H. Levine, K. P. Davis, F. S. Bates, D. A. Hammer and M. J. Therien, Macromolecules, 2006, 39, $1673-1675$.

10 L. Zhang and A. Eisenberg, Macromolecules, 1999, 32, 2239-2249.

11 E. V. Konishcheva, U. E. Zhumaev and W. P. Meier, Macromolecules, 2017, 50, 1512-1520.

12 C. Nardin, T. Hirt, J. Leukel and W. Meier, Langmuir, 2000, 16, 1035-1041.

13 M. S. Bretscher, Nature (London), New Biol., 1972, 236, 11.

14 P. F. Devaux, Biochemistry, 1991, 30, 1163-1173.

15 R. Stoenescu and W. Meier, Chem. Commun., 2002, 3016-3017.

16 R. Stoenescu, A. Graff and W. Meier, Macromol. Biosci., 2004, 4, 930-935.

17 F. Liu and A. Eisenberg, J. Am. Chem. Soc., 2003, 125, 15059-15064. 18 A. F. Mason and P. Thordarson, ACS Macro Lett., 2016, 5, 1172-1175.

19 A. Wittemann, T. Azzam and A. Eisenberg, Langmuir, 2007, 23, 2224-2230.

20 G. Liu, S. Ma, S. Li, R. Cheng, F. Meng, H. Liu and Z. Zhong, Biomaterials, 2010, 31, 7575-7585.

21 Q. Liu, J. Chen and J. Du, Biomacromolecules, 2014, 15, 3072-3082.

22 J. N. Israelachvili, Intermolecular and Surface Forces, 1991.

23 S. Schrage, R. Sigel and H. Schlaad, Macromolecules, 2003, 36, 1417-1420.

24 O. Casse, A. Shkilnyy, J. Linders, C. Mayer, D. Häussinger, A. Völkel, A. F. Thünemann, R. Dimova, H. Cölfen, W. Meier, H. Schlaad and A. Taubert, Macromolecules, 2012, 45, 4772-4777.

25 O. Terreau, L. Luo and A. Eisenberg, Langmuir, 2003, 19, 5601-5607.

26 C. J. Mable, R. R. Gibson, S. Prevost, B. E. McKenzie, O. O. Mykhaylyk and S. P. Armes, J. Am. Chem. Soc., 2015, 137, 16098-16108.

27 A. Walther, C. Barner-Kowollik and A. H. E. Müller, Langmuir, 2010, 26, 12237-12246.
28 A. Sundararaman, T. Stephan and R. B. Grubbs, J. Am. Chem. Soc., 2008, 130, 12264-12265.

29 P. Bhargava, Y. Tu, J. X. Zheng, H. Xiong, R. P. Quirk and S. Z. D. Cheng, J. Am. Chem. Soc., 2007, 129, 1113-1121.

30 A. O. Moughton, J. P. Patterson and R. K. O'Reilly, Chem. Commun., 2011, 47, 355-357.

31 I. LaRue, M. Adam, M. Pitsikalis, N. Hadjichristidis, M. Rubinstein and S. S. Sheiko, Macromolecules, 2006, 39, 309-314.

32 S. Abbas, Z. Li, H. Hassan and T. P. Lodge, Macromolecules, 2007, 40, 4048-4052.

33 Q. Chen, H. Schönherr and G. J. Vancso, Small, 2010, 6, 2762-2768.

34 C. Maiti, R. Banerjee, S. Maiti and D. Dhara, Langmuir, 2015, 31, $32-41$.

35 J. R. Lovett, N. J. Warren, S. P. Armes, M. J. Smallridge and R. B. Cracknell, Macromolecules, 2016, 49, 1016-1025.

36 M. Lee, S.-J. Lee and L.-H. Jiang, J. Am. Chem. Soc., 2004, 126, 12724-12725.

37 T.-H. Ku, M.-P. Chien, M. P. Thompson, R. S. Sinkovits, N. H. Olson, T. S. Baker and N. C. Gianneschi, J. Am. Chem. Soc., 2011, 133, 8392-8395.

38 X. Ji, H. Wang, Y. Li, D. Xia, H. Li, G. Tang, J. L. Sessler and F. Huang, Chem. Sci., 2016, 7, 6006-6014.

39 M. C. M. van Oers, F. P. J. T. Rutjes and J. C. M. van Hest, J. Am. Chem. Soc., 2013, 135, 16308-16311.

40 N. J. W. Penfold, J. R. Lovett, P. Verstraete, J. Smets and S. P. Armes, Polym. Chem., 2017, 8, 272-282.

41 R. Deng, M. J. Derry, C. J. Mable, Y. Ning and S. P. Armes, J. Am. Chem. Soc., 2017, 139, 7616-7623.

42 M. R. Molla, P. Prasad and S. Thayumanavan, J. Am. Chem. Soc., 2015, 137, 7286-7289.

43 E. Konishcheva, D. Häussinger, S. Lörcher and W. Meier, Eur. Polym. J., 2016, 83, 300-310.

44 O. Sedlacek, B. D. Monnery, S. K. Filippov, R. Hoogenboom and M. Hruby, Macromol. Rapid Commun., 2012, 33, 1648-1662.

45 M. Meldal and C. W. Tornøe, Chem. Rev., 2008, 108, 2952-3015.

46 J.-F. Lutz, Angew. Chem., Int. Ed., 2007, 46, 1018-1025.

47 R. Hoogenboom, B. C. Moore and U. S. Schubert, Chem. Commun., 2006, 4010-4012.

48 J. Ries and P. Schwille, BioEssays, 2012, 34, 361-368.

49 K. Knop, R. Hoogenboom, D. Fischer and U. S. Schubert, Angew. Chem., Int. Ed., 2010, 49, 6288-6308.

50 R. Hoogenboom, Angew. Chem., Int. Ed., 2009, 48, 7978-7994.

51 K. Bacia, S. A. Kim and P. Schwille, Nat. Methods, 2006, 3, 83.

52 V. Buschmann, B. Krämer, F. Koberling, R. Macdonald and S. Rättinger, Application Note PicoQuant, GmbH, Berlin, 2009.

53 E. V. Konishcheva, U. E. Zhumaev, M. Kratt, V. Oehri and W. Meier, Macromolecules, 2017, 50, 7155-7168. 